\title{
FLUX Events: \\ Current trends in contemporary media arts
}

\author{
Aphra Shemza \\ Artist, UK \\ aphrashemza@gmail.com
}

\author{
Oliver Gingrich \\ Artist, UK \\ olivergingrich@gmail.com
}

\author{
Maria Almena \\ Artist, UK \\ maria@kimatica.net
}

\section{FLUX: A PLATFORM FOR MEDIA ART}

FLUX is a forum hosted by artists to discuss strategies, processes and collective themes within the media arts. FLUX is a fluid platform committed to media artists working right NOW in the UK. We hold bi-monthly events, which are curated by one of the hosts and facilitate the exchange of ideas, as media artists come together to profile their work. Performances, talks and showcases of artwork provide a forum for artistic discourse and exchange. Hosted in different London venues and supported by the British Computer and Arts Society, these larger events offer a space for the exchange of creativity, inspiration and support.

The panel discussion at EVA London 2018 will be chaired by Guy Armitage and provide an insight into the underground world of contemporary media artists, why it is so important and open the discussion up about collective themes emerging in the art scene. Guy Armitage is Founder and CEO of Zealous, a London-based start-up matching creative talent with opportunities. Guy has been published in Forbes and Metro, where he has advocated the importance of creativity in the UK economy. As well as speaking at TEDx, CreativeXPO and various UK universities, Guy also hosts panel talks covering key subjects such as the value of creativity, IP and copyright, attitudes to the digital landscape, PR and Marketing, Women in creativity and branding for artists. Armitage has been a spearhead for promoting the importance of creativity in the UK economy and has advocated the creation of a new category for the media artists within this promoting their importance to the masses. The panel will invite the audience to ask questions and voice their views on the future of media art networks in the UK.

Each of the three FLUX hosts will provide an overview about their organization and why it is so necessary to build networks today. The discussion will reflect strategies and collective themes within the media arts, such as light, transcendence, spirituality, nature, technology, biology and many more. FLUX Events will present the wide-ranging array of artists that the organization has worked with and include examples of events and exhibitions that they have held within the last year.

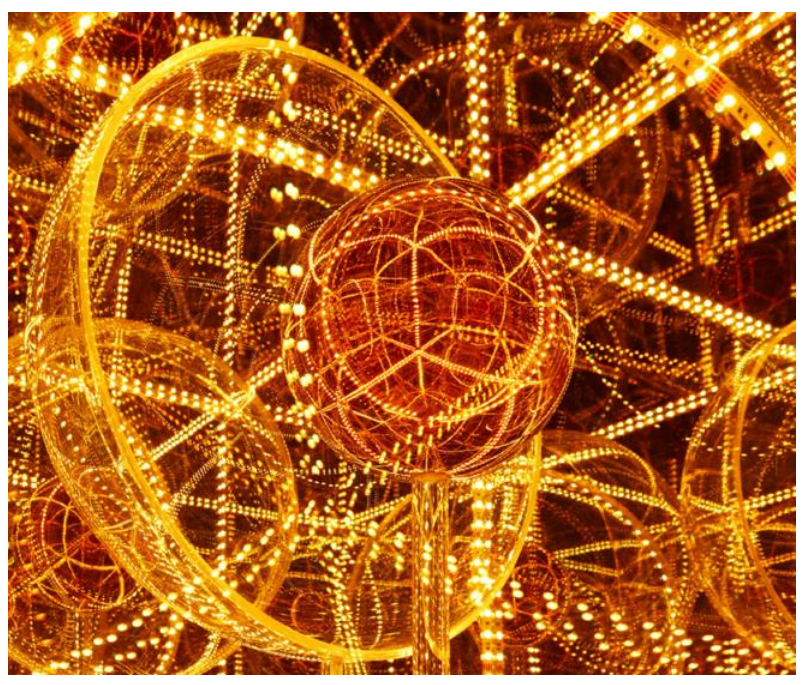

Figure 1: Aphra Shemza: Composition X.

\section{WHY FLUX?}

Created by artists Aphra Shemza, Maria Almena and Oliver Gingrich, FLUX fills a void in the UK media arts institutions. Disconnected and fragmented, media artists in the UK felt the need to re-connect, change ideas, to seek conceptual discourse and debate. FLUX is a movement of media artists working on the cusp of technological development, using light, sound, movement and other media to challenge perception and to facilitate social change. We understand technology as an enabler, a tool not for the few, but for the public to explore, interact with, to create. FLUX is about a discourse on technology and art, as a method of empowerment, self-realisation, the challenging of norms and conventions, to reach beyond, and to change our perception of the world we create. Other than most European countries or 
the US, the UK's media art landscape is characterised by a lack of major institutions for contemporary media arts. Whereas galleries are bridging this gap in Germany or the US, or institutions such as the ZKM in Karlsruhe, the Musée de la Gaité Lyrique in Paris are playing a key role in communicating technology facilitated art to the wider public, the UK's lack of major institutions is only compensated for by irregular, large-scale museums shows at the V\&A or the Barbican. The absence of a permanent hub for media creation and display has stimulated selforganisation among artists working with new media.

\section{WHO WE ARE}

With a distinctive focus on media art practice, the three founders of FLUX enjoyed synergetic crossover: Oliver Gingrich background is in Fine Arts (MA Fine Arts CSM) and Art and technology. Oliver's professional practise focuses on immersive projection technology (holographic projection), working as Art Director at MDH Hologram. Oliver completed his Doctorate with a focus presence research and holographic projection art. As part of Analema Group, he co-created major immersive installations at Roundhouse London or the Union Chapel. As co-founder of FLUX Events, he has a special focus on research, the principles of illusion and immersion.

Maria Almena is a creative director and a multimedia artist, co-founder of the London-based creative studio, Kimatica Studio. A UK pioneer studio in digital performances, their artistic practise explores concepts of human consciousness and perception, making those transcendental ideas accessible to a modern audience, to inspire reconnection with the magical thinking.

Aphra Shemza is a London based new media artist working with abstraction, interactivity and light. Shemza has a background in the arts having worked for Kinetica Museum, Faggionato Fine Art and Amrita Jhaveri in the past. Academically she has been published in Tate Etc. magazine and given talks at Tate Britain, the Courtauld Institute and EVA 2017, to name but a few. Last year she exhibited her work in the Shard with Louis Roederer Champagne, Winter Lights Festival, Canary Wharf and Xi'an Maker Faire with the British Council.

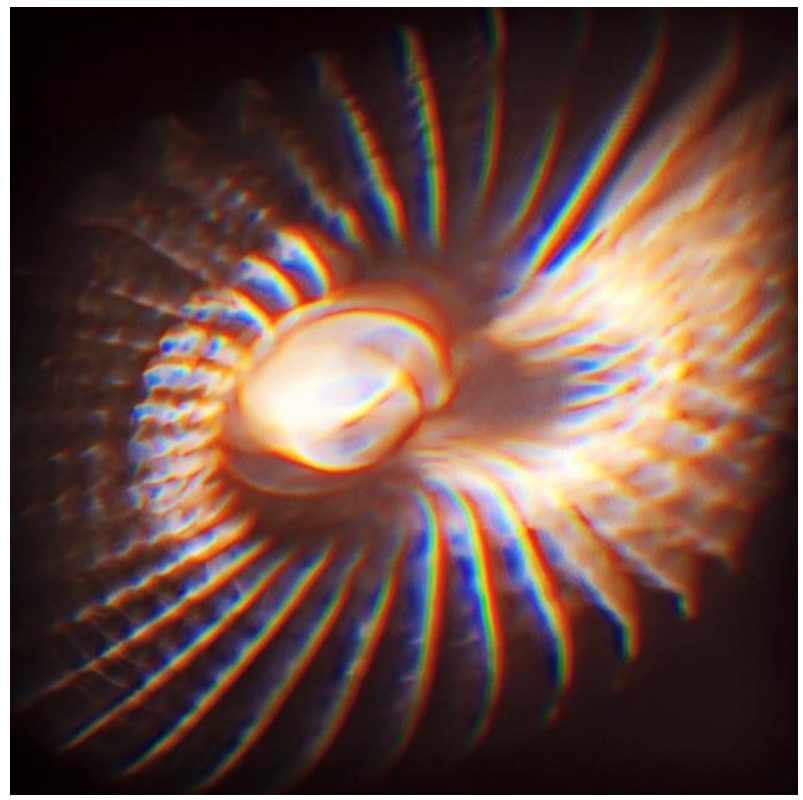

Figure 2: Oliver Gingrich: Refraction II (2017).

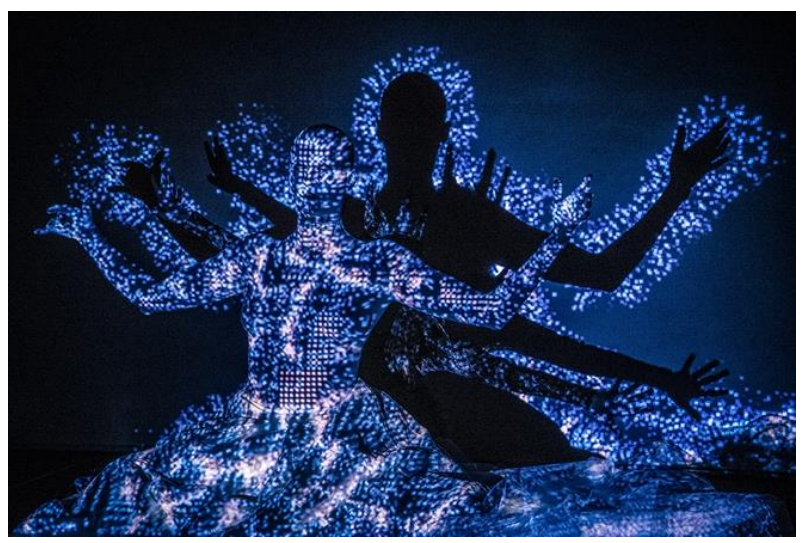

Figure 3: Kimatica: Transcendence (2017).

\section{REFERENCES}

Analema Group. http://analemagroup.com (retrieved 27 March 2018).

Aphra Shemza. http://www.aphrashemza.com (retrieved 27 March 2018).

Flux Events. http://www.fluxevents.co.uk (retrieved 27 March 2018).

Kimatica. http://www.kimatica.net (retrieved 27 March 2018).

Oliver Gingrich. http://olivergingrich.com (retrieved 27 March 2018). 